\title{
mRNA expression of TLR4, TLR9 and NF- $\kappa B$ in a neonatal murine model of necrotizing enterocolitis
}

\author{
YIYU YIN $^{1 *}$, FENGLI LIU $^{2 *}$, YIPING LI $^{3}$, RUZE TANG $^{1}$ and JIAN WANG ${ }^{1}$ \\ ${ }^{1}$ Children's Hospital of Soochow University, Suzhou, Jiangsu 215025; ${ }^{2}$ Xuzhou Children's Hospital, \\ Xuzhou, Jiangsu 221006; ${ }^{3}$ Pediatric Research Institute of Soochow University, Suzhou, Jiangsu 215025, P.R. China
}

Received January 8, 2016; Accepted June 28, 2016

DOI: $10.3892 / \mathrm{mmr} .2016 .5455$

\begin{abstract}
A neonatal model of necrotizing enterocolitis (NEC) in mice was established to examine the role of Toll-like receptors (TLRs) 4 and 9 , and of nuclear factor (NF)- $\kappa$ B by quantitative detection of their mRNAs in intestinal tissue during the occurrence of NEC, and thus aid in the understanding of the basic pathogenesis of NEC. A total of 50 newborn BALB/c mice (specific pathogen-free level) ranging in age from 7 to 10 days, of either gender, and weighing 4.8-5.4 $\mathrm{g}$ were selected and randomly divided into a control and test group, $\mathrm{n}=25$ mice per group. Mice in the control group were kept in the same cage with the mother who fed them, free from any interventions. Mice in the test group were separated from their mother $48 \mathrm{~h}$ following birth and placed in an incubator, artificially fed with milk substitutes, and regularly treated with hypoxia and cold stimulation (100\% nitrogen anoxia for $90 \mathrm{sec}$, cold stimulation at $4^{\circ} \mathrm{C}$ for $10 \mathrm{~min}, 3$ times a day for 3 days) to induce the neonatal NEC. The general state and body weight variations of the mice were recorded, the mice were sacrificed and the intestinal tissue necrosis was evaluated visually, the degree of intestinal injury was determined by histopathological staining, and the mRNA expression levels of intestinal tissue TLR4, TLR9 and NF- $\kappa$ B were quantified. Of the 25 mice in the test group, 3 died a natural death and 22 were sacrificed; their general state was worse than that of the mice in the control group, and the body weight variations among them were considerably larger. NEC was confirmed in 12 cases by visual inspection, and the average histological scores of the mice in the test group were $3.5 \pm 0.6$, significantly higher than that in the control group $(\mathrm{P}<0.05)$. The mRNA expression of TLR4 and $N F-\kappa B$ in the test group were significantly higher than in
\end{abstract}

Correspondence to: Dr Jian Wang, Children's Hospital of Soochow University, 92 Zhongnan Street, Suzhou, Jiangsu 215025, P.R. China

E-mail: jian_wang111@163.com

*Contributed equally

Key words: necrotizing enterocolitis, neonatal mouse model, Toll-like receptor, nuclear factor- $\kappa \mathrm{B}, \mathrm{mRNA}$ the control group. By contrast, the mRNA expression of TLR9 was significantly lower in the test group, and differences were statistically significant $(\mathrm{P}<0.05)$. Thus, the increased mRNA expression of TLR4 and NF- $\kappa \mathrm{B}$, and decreased mRNA expression of TLR9 during NEC may be an important inflammatory mechanism of the disease.

\section{Introduction}

Necrotizing enterocolitis (NEC) is the most common neonatal gastrointestinal emergency and occurs mostly in premature infants of very low birth weight with a morbidity rate of $\leq 7 \%$ and a fatality rate of $15-30 \%$ (1). Individuals affected by NEC often suffer different degrees of complications, including intestinal obstruction, short bowel syndrome, intestinal perforation, growth retardation, and even intestinal paralysis, intestinal necrosis, systemic inflammatory response syndrome and multiple organ failure, and the mortality rate is $\leq 100 \%(2,3)$.

At present, NEC is considered a multifactorial disease where different circumstances such as prematurity, artificial feeding, hypoxia ischemia, inflammatory reactions and abnormal bacterial colonization, are incorporated in an inflammatory cascade reaction that leads to pathogenesis of the disease (4).

In the present study, neonatal mouse models of NEC were established, and mRNA expression of Toll-like receptor (TLR) 4, TLR9 and nuclear factor (NF)- $\mathrm{B}$ in intestinal tissue was detected in an effort to better understand the immunological mechanisms leading to the occurrence of NEC and thus provide a fundamental basis on which to improve treatment approaches against NEC.

\section{Materials and methods}

Animals. Fifty newborn BALB/c, specific pathogen-free level mice, ranging in age from 7 to 10 days and weighing 4.8-5.4 g, of either gender were provided for this study by the Experimental Animal Center of Xuzhou Medical College (Xuzhou, China). The study was approved by the ethics committee of Xuzhou Medical College. The mice were kept in an artificial $12 \mathrm{~h}$ light/dark cycle, at $28-30^{\circ} \mathrm{C}$ and $45-65 \%$ humidity. The mice were randomly divided into the control $(n=25)$ and test $(n=25)$ groups. The mice in the control group were kept in the same cage with the mouse mother and allowed to feed, free 
from any interventions. By contrast, the mice in the test group were isolated from the mother and artificially fed to induce the development of NEC as described below.

Materials. Specialized instruments used in the study included: a BX50 microimaging system (Olympus Corp., Tokyo, Japan), a RM2255 Paraffin section machine (Leica, Mannheim, Germany), and a CY-100 oxygen concentration determinator (Zhejiang Second Plant of Xinanjiang Analytical Instrument, Zhejiang, China).

The reagents used to feed and treat the NEC mice were: Ensure nutrition powder (Abbott Laboratories, Abbott Park, IL, USA), Wyeth S-26 SMA PDF Gold (Wyeth Pharmaceuticals, Philadelphia, PA, USA) medium and long chain fat emulsion injection (SSPC) and 100\% nitrogen (Xuzhou Multi-Gas Industry Co., Ltd., Xuzhou, China).

NEC model construction. The test mice were separated from their mothers $48 \mathrm{~h}$ after birth and placed into incubators (28-30 ${ }^{\circ} \mathrm{C}$ and $45-65 \%$ humidity). The mice were fed using mouse milk substitutes containing $116.3 \mathrm{~g} / 1$ fat, $107 \mathrm{~g} / 1$ protein, $27 \mathrm{~g} / \mathrm{l}$ sugar, and $6,616 \mathrm{~kJ} / \mathrm{l}$ calories, prepared based on the methods of Tonkiss et al (5). A gavage tube (a closed intravenous catheter system connected to a $1 \mathrm{ml}$ injection syringe) was used to portion the servings through the mount $(1.5-2.0 \mathrm{~cm}$ deep). The initial feeding amount was $0.15 \mathrm{ml}$, after which $0.1 \mathrm{ml}$ were added every $24 \mathrm{~h}$. Additionally, to induce NEC, the mice in the test group were placed in a hypoxic chamber with pure nitrogen at $10 \mathrm{l} / \mathrm{min}$ for $90 \mathrm{sec}$ and then into a refrigerator at $4^{\circ} \mathrm{C}$ for $10 \mathrm{~min}$ to induce hypothermia. The same procedure was repeated every day at 9 a.m, and 3 and 9 p.m. for a total of 3 days. After the last anoxia and cold stimulation, the mice were fasted for $12 \mathrm{~h}$ and then sacrificed via cervical dislocation. The control group mice were also sacrificed at the same time $(6,7)$.

Sample collection and processing. The chest of the mice was opened and blood was drawn from the heart in a sterile environment. The abdominal skin was cleaned and disinfected and the enterocelia opened from the median line of abdomen with clean eye scissors, the mesentery and blood vessels were carefully isolated with eye tweezers, then the intestinal tube between the lower end of duodenum and the ileocecus was removed. To prepare the intestinal tube, $3 \mathrm{~cm}$ from the terminal ileum was cut, and the ileum was divided into upper and lower segments. The upper segment was immersed in $10 \%$ neutral formalin for examination, the lower segment was rinsed with iced phosphate buffer $(\mathrm{pH} 7.4)$ and stored at $-80^{\circ} \mathrm{C}$ until use.

Observation index. General state and body weight variations were recorded. Specific details observed included: Mental state, reaction time and general activity, food intake, abdominal distension, milk vomiting, gastric retention and stool deposition. The weights were recorded and the mortality rate was calculated.

Variations of the general morphology of intestinal tissues were assessed. The abdominal cavity was opened and any color or luster changes were noted, and the presence of enteric cavity pneumatosis, necrosis or hemorrhage was visually checked.

The pathological scoring of tissues was carried out as follows: the fixed ileum specimen tissues were conventionally
Table I. Pathological score standard for intestinal tissues.

\begin{tabular}{ll} 
Score & \multicolumn{1}{c}{ Pathological changes } \\
\hline 0 & $\begin{array}{l}\text { Complete intestinal villi and epithelia, normal } \\
\text { tissue structures }\end{array}$ \\
1 & $\begin{array}{l}\text { Swelling and mild separation under the mucosal } \\
\text { membrane and/or lamina propria }\end{array}$ \\
2 & $\begin{array}{l}\text { Swelling and moderate separation under mucosal } \\
\text { membrane and/or lamina propria, edema under } \\
\text { mucous membrane and/or muscle layer }\end{array}$ \\
3 & $\begin{array}{l}\text { Swelling and severe separation under mucosal } \\
\text { membrane and/or lamina propria, edema under } \\
\text { mucous membrane and/or muscle layer, focal } \\
\text { villi absence }\end{array}$ \\
& Absence of intestinal villi, bowel necrosis present
\end{tabular}

dehydrated, and the tissues were embedded in paraffin. Serial sections $(3 \mu \mathrm{m})$ were excised and stained by hematoxylin and eosin. Two pathology doctors, who made double-blind scorings according to a given standard, observed the pathological changes of all the section tissues under light microscopy (Olympus, Tokyo, Japan). The top scores obtained from the samples confirmed the degree of damage of the intestinal tract, and histological scores $\geq 2$ were identified as NEC (Table I).

Quantitative polymerase chain reaction (TaqMan probe) and the SYBR-Green I fluorochrome method were used to detect the mRNA expression of TLR4, TLR9 and NF- $\kappa$ B. The standard curves of target genes (TLR4, TLR 9 and $N F-\kappa B$ ) and housekeeping genes $(G A P D H)$ were created and used to quantify the expression of the tested mRNAs. Following reverse transcription and amplification the relative expression amounts of TLRs and NF- $\mathrm{NB}$ in each group were determined. The values for each test were normalized using the GAPDH housekeeping mRNA.

Statistical analysis. SPSS 20.0 statistical software (IBM SPSS, Armonk, NY, USA) was used to perform statistical analyses. Measurement data are presented as mean \pm standard deviation. The t-test was applied for comparisons between groups, and the Kruskal-Wallis $\mathrm{H}$ was applied to the pathological scoring of intestinal tissues. Enumeration data are presented as percentages (\%), and the $\chi^{2}$ test was applied in comparisons between groups. $\mathrm{P}<0.05$ was considered to indicate a statistically significant difference.

\section{Results}

General data. In the test group, 3 cases died a natural death and 22 cases were sacrificed; in the control group, 2 cases died a natural death and 23 cases were sacrificed, and the difference in mortality between the two groups was not statistically significant $(\mathrm{P}>0.05)$. Mice in the test group were in a poor general status, their mental state, reaction time and activity state were poor, they fed only occasionally, and had a high incidence of abdominal distension, milk vomiting, gastric retention and watery stools in large amounts. The general state and body weights of mice in the test group were clearly 
different than those in the control group. From the test group, 12 cases were confirmed to have developed NEC by visual inspection, and proved the NEC modeling was successful in almost $50 \%$ of the individuals in the group.

Comparison of histological scores. The average histological scores of the mice in the test group that developed NEC were 2-3 points while the score for the animals in the control group were mostly $<2$ points. The NEC animals showed a significantly higher score than the animals in the control group, and the difference was statistically significant $(\mathrm{P}<0.05$; Table II).

Comparison of mRNA expression levels of TLR4, TLR9 and $N F-\kappa B$. The mRNA expression of TLR 4 and NF- $\kappa B$ in the test group was significantly higher than that in the control group, while the mRNA expression of TLR9 was significantly lower in the test group. The differences observed were statistically significant $(\mathrm{P}<0.05$; Table III).

\section{Discussion}

It is widely accepted that NEC is the result of the simultaneous action of many factors with an inflammatory cascade as the final common pathway leading to the development of NEC. This inflammation theory involves a large number of inflammatory mediators, receptors and signal transduction pathways, intestinal wall edema and necrosis, a reduced mucosal barrier function, secondary bacterial translocation and results in pneumatosis intestinalis, which in turn activate the immune response system of the body or even lead to multiple organ dysfunction syndrome and death (8-10).

TLRs are members of the innate immune pattern recognition receptor family. They are widely expressed in human tissues and can identify and combine with pathogen-associated molecular patterns, trigger a series of signal transductions, lead to the release of inflammatory mediators and activate the acquired immune system. TLRs are a bridge between innate and acquired immunity (11-13). TLR4 was the first human TLR to be described and is the most well studied of the TLRs. TLR4 is a type I transmembrane protein comprising intracellular, transmembrane and extracellular domains composed of three parts. The main ligands of TLR4 are G-lipopolysaccharides (LPS) (14-16). TLR4 may not recognize LPS and induce the downstream signal transduction independently. The LPS recognition receptor complex with high affinity and signal transduction function formed by CD14, myeloid differentiation protein 2 and LPS binding protein is needed. NF- $\kappa \mathrm{B}$ is subsequently activated through a non-signaling-dependent pathway and is transferred from cytoplasm to the nucleus, where it combines with the $\mathrm{NF}-\kappa \mathrm{B}$ binding site in the promoter region of the inflammatory reaction regulating gene to initiate inflammatory cytokine gene transcription, translation and massive release and stimulate the body's immune response to respond against gram-negative bacteria $(17,18)$.

In recent years, the role of TLR4 in the pathogenesis of NEC has aroused a lot of attention (19). The expression of TLR4 in normal intestinal epithelial cells was low while a high level was identified in NEC children and animal models. A high expression of TLR4 was identified even before NEC tissue injury. High risk factors for NEC, including premature
Table II. Comparison of histological scores.

\begin{tabular}{lccccr}
\hline Group & $\begin{array}{c}\text { No. of } \\
\text { individuals }\end{array}$ & $\begin{array}{c}\text { Average } \\
\text { scores }\end{array}$ & $<2$ & $2-3$ & 4 \\
\hline NEC & 12 & $3.5 \pm 0.6$ & 1 & 9 & 2 \\
Control & 25 & $1.2 \pm 0.3$ & 23 & 2 & 0 \\
t-test $\left(\chi^{2}\right)$ & & 3.527 & 5.274 & & \\
P-value & & 0.013 & $<0.001$ & & \\
\hline
\end{tabular}

NEC, necrotizing enterocolitis.

Table III. Comparison of mRNA expression levels of TLR4, TLR9 and NF- $\mathrm{KB}$.

\begin{tabular}{lccc}
\hline Group & TLR 4 & TLR9 & NF-кB \\
\hline Control & $2.03 \pm 0.41$ & $0.24 \pm 0.02$ & $1.67 \pm 0.25$ \\
Test & $0.12 \pm 0.03$ & $1.52 \pm 0.36$ & $0.33 \pm 0.04$ \\
t-test & 4.527 & 5.012 & 5.367 \\
P-value & $<0.001$ & $<0.001$ & $<0.001$ \\
\hline
\end{tabular}

TLR, Toll-like receptor; NF- $\kappa \mathrm{B}$, nuclear factor- $\kappa \mathrm{B}$.

birth, artificial feeding, hypoxia ischemia, and bacterial infections, can stimulate TLR4 expression to increase (20). The role of TLR4 in the pathogenesis of NEC has mainly been associated with inflammation and repair processes (11). Activated TLR4 can activate $\mathrm{NF}-\kappa \mathrm{B}$, and then induce the upregulated expression of downstream inflammatory cytokines. $\mathrm{NF}-\kappa \mathrm{B}$ in intestinal tissues from animal models and NEC children showed a sustained high expression while the expression of the inflammatory cytokines such as tumor necrosis factor $\alpha$, interleukin (IL)-6 and IL-8, also increased. A large number of inflammatory mediators lead to damage in intestinal epithelial cells and mucosal defense mechanisms, which subsequently develop NEC. Inhibiting the TLR4 pathway can significantly reduce the expression of inflammatory mediators, alleviate macrophage infiltration, and reduce the occurrence of bacterial translocation $(21,22)$. Animal experiments have confirmed that NEC occurrence and intestinal tissue damage occur less often in TLR4-deficient mutant mice $(\mathrm{C} 3 \mathrm{H} / \mathrm{HeJ})$ than in TLR4 wild-type mice $(\mathrm{C} 3 \mathrm{HeB} / \mathrm{FeJ})$.

Besides TLR4, TLR9 has also gained attention from scientists studying NEC. TLR9 is a bacterial DNA receptor that mediates the response of host cells to bacterial DNA by identifying CPG-DNA (23). The expression of TLR4 and TLR9 in NEC children and animal models shows opposite trends. TLR4 expression increases while TLR9 expression decreases (24). Following activation by CPG-DNA, TLR9 can inhibit the TLR4 signaling pathway, suppress $\mathrm{NF}-\kappa \mathrm{B}$ activation and translocation, reduce apoptosis, and bacterial translocation, and thus decrease the amount of deterioration of NEC (25).

Differing from previous studies that established neonatal rat models, in this study the model was in established in mice 
to provide a reference for future animal experiments. The results of the present study showed 12 cases of NEC in the test group, confirmed by visual inspection. The success rate of modeling was $48 \%$, and the average histological scores of the mice in the test group were significantly higher than those in the control group. Similarly, the mRNA expressions of TLR4 and $\mathrm{NF}-\kappa \mathrm{B}$ in the test group were significantly higher than those in the control group, and the mRNA expression of TLR9 was significantly lower in the test group.

In conclusion, an increased mRNA expression of TLR4 and $N F-\kappa B$, and a decreased mRNA expression of TLR 9 may be important inflammatory immune mechanisms of NEC. These findings offer new ideas for the subsequent development of alternative treatment approaches against NEC.

\section{References}

1. Berman L and Moss RL: Necrotizing enterocolitis: An update. Semin Fetal Neonatal Med 16: 145-150, 2011.

2. Neu J and Walker WA: Necrotizing enterocolitis. N Engl J Med 364: 255-264, 2011.

3. Liu Y, Zhu L, Fatheree NY, Liu X, Pacheco SE, Tatevian N and Rhoads JM: Changes in intestinal Toll-like receptors and cytokines precede histological injury in a rat model of necrotizing enterocolitis. Am J Physiol Gastrointest Liver Physiol 297 G442-G450, 2009.

4. Dvorak B: Milk epidermal growth factor and gut protection. J Pediatr 156 (Suppl 2): S31-S35, 2010.

5. Tonkiss J, Smart JL, Auestad NS, Edmond J: Type of milk substitute influences growth of the gastrointestinal tract in artificially reared rat pups. J Pediatr Gastroenterol Nutr 4: 818-825, 1985.

6. Claud EC: Neonatal necrotizing enterocolitis -inflammation and intestinal immaturity. Antiinflamm Antiallergy Agents Med Chem 8: 248-259, 2009

7. Grave GD, Nelson SA, Walker WA, Moss RL, Dvorak B, Hamilton FA, Higgins R and Raju TN: New therapies and preventive approaches for necrotizing enterocolitis: Report of a research planning workshop. Pediatr Res 62: 510-514, 2007.

8. Kaczorowski DJ, Nakao A, McCurry KR and Billiar TR: Toll-like receptors and myocardial ischemia/reperfusion, inflammation, and injury. Curr Cardiol Rev 5: 196-202, 2009.

9. Yamamoto $\mathrm{M}$ and Takeda $\mathrm{K}$ : Current views of toll-like receptor signaling pathways. Gastroenterol Res Pract 2010: 240365, 2010.

10. Nanthakumar N, Meng D, Goldstein AM, Zhu W, Lu L, Uauy R, Llanos A, Claud EC and Walker WA: The mechanism of excessive intestinal inflammation in necrotizing enterocolitis: an immature innate immune response. PLoS One 6: e17776, 2011.

11. Jilling T, Simon D, Lu J, Meng FJ, Li D, Schy R, Thomson RB, Soliman A, Arditi M and Caplan MS: The roles of bacteria and TLR4 in rat and murine models of necrotizing enterocolitis. J Immunol 177: 3273-3282, 2006.
12. Leaphart CL, Cavallo J, Gribar SC, Cetin S, Li J, Branca MF, Dubowski TD, Sodhi CP and Hackam DJ: A critical role for TLR4 in the pathogenesis of necrotizing enterocolitis by modulating intestinal injury and repair. J Immunol 179: 4808-4820, 2007.

13. Le Mandat Schultz A, Bonnard A, Barreau F, Aigrain Y, Pierre-Louis C, Berrebi D and Peuchmaur M: Expression of TLR-2, TLR-4, NOD2 and pNF- $\kappa \mathrm{B}$ in a neonatal rat model of necrotizing enterocolitis. PLoS One 2: e1102, 2007.

14. Chan KL, Wong KF and Luk JM: Role of LPS/CD14/TLR4mediated inflammation in necrotizing enterocolitis: Pathogenesis and therapeutic implications. World J Gastroenterol 15: 4745-4752, 2009.

15. Gribar SC, Sodhi CP, Richardson WM, Anand RJ, Gittes GK, Branca MF, Jakub A, Shi XH, Shah S, Ozolek JA, et al: Reciprocal expression and signaling of TLR4 and TLR9 in the pathogenesis and treatment of necrotizing enterocolitis. J Immunol 182: 636-646, 2009

16. Cario E: Toll-like receptors in inflammatory bowel diseases: A decade later. Inflamm Bowel Dis 16: 1583-1597, 2010.

17. Yoon HS: Neonatal innate immunity and Toll-like receptor. Korean J Pediatr 53: 985-988, 2010.

18. Rhee SH: Basic and translational understandings of microbial recognition by toll-like receptors in the intestine. J Neurogastroenterol Motil 17: 28-34, 2011.

19. Sodhi CP, Shi XH, Richardson WM, Grant ZS, Shapiro RA, Prindle T Jr, Branca M, Russo A, Gribar SC, Ma C, et al: Toll-like receptor-4 inhibits enterocyte proliferation via impaired $\beta$-catenin signaling in necrotizing enterocolitis. Gastroenterology 138: 185-196, 2010.

20. Dai S, Sodhi C, Cetin S, Richardson W, Branca M, Neal MD, Prindle T, Ma C, Shapiro RA, Li B, et al: Extracellular high mobility group box-1 (HMGB1) inhibits enterocyte migration via activation of Toll-like receptor- 4 and increased cell-matrix adhesiveness. J Biol Chem 285: 4995-5002, 2007.

21. Cetin S, Ford HR, Sysko LR, Agarwal C, Wang J, Neal MD, Baty C, Apodaca G and Hackam DJ: Endotoxin inhibits intestinal epithelial restitution through activation of Rho-GTPase and increased focal adhesions. J Biol Chem 279: 24592-24600, 2004.

22. Spehlmann ME and Eckmann L: Nuclear factor-kappa B in intestinal protection and destruction. Curr Opin Gastroenterol 25: 92-99, 2009.

23. Good M, Sodhi CP, Ozolek JA, Buck RH, Goehring KC, Thomas DL, Vikram A, Bibby K, Morowitz MJ, Firek B, Lu P and Hackam DJ: Lactobacillus rhamnosus HN001 decreases the severity of necrotizing enterocolitis in neonatal mice and preterm piglets: Evidence in mice for a role of TLR9. Am J Physiol Gastrointest Liver Physiol 306: G1021-G1032, 2014.

24. Arciero J, Bard EG, Siggers R, Afrazi A, Hackam D, Vodovotz Y and Rubin J: Modeling the interactions of bacteria and Toll-like receptor-mediated inflammation in necrotizing enterocolitis. J Theor Biol 321: 83-99, 2013.

25. De Plaen IG, Liu SX, Tian R, Neequaye I, May MJ, Han XB, Hsueh W, Jilling T, Lu J and Caplan MS: Inhibition of nuclear factor-kappaB ameliorates bowel injury and prolongs survival in a neonatal rat model of necrotizing enterocolitis. Pediatr Res 61: 716-721, 2007. 